\title{
AN ENCOURAGING STRATEGY IN PEER CORRECTION
}

\author{
Associate Professor Gulnara Ahmadova \\ Azerbaijan, Baku, Azerbaijan State \\ Oil and Industry University
}

DOI: https://doi.org/10.31435/rsglobal_ws/30112019/6787

\section{ARTICLE INFO}

Received: 12 September 2019

Accepted: 12 November 2019

Published: 30 November 2019

\section{KEYWORDS}

peer,

correction,

speaking,

evaluation,

error,

activity,

point system.

\begin{abstract}
The purpose of the article is to introduce a strategy in the peer correction. Any correction of the mistake being reluctantly welcomed is usually accepted with a sense of disfavor. Peer correction in speaking activity is no exception. To turn this tedious process into an attractive one we have developed a relatively new strategy. Peer correction in writing activity has long been practiced. Learners enjoy discovering each other's mistakes in essays, spelling or grammar tests, etc. But correcting speaker's errors being rarely carried out has gradually almost been forgotten. The paper introduces a new concept in peer correction involving a point system. The students actively participating in a correction process are praised with a surplus point for a corrected mistake, which is further taken into account. The strategy has proved to be a motivating one in teaching English as a foreign language.
\end{abstract}

Citation: Gulnara Ahmadova. (2019) An Encouraging Strategy in Peer Correction. World Science. 11(51), Vol.4. doi: 10.31435/rsglobal_ws/30112019/6787

Copyright: (C) 2019 Gulnara Ahmadova. This is an open-access article distributed under the terms of the Creative Commons Attribution License (CC BY). The use, distribution or reproduction in other forums is permitted, provided the original author(s) or licensor are credited and that the original publication in this journal is cited, in accordance with accepted academic practice. No use, distribution or reproduction is permitted which does not comply with these terms.

Introduction. Peer correction has long been known as not to be appreciated by most students. Nowadays correction of the written task is more or less frequently being held by the instructors. It is widely used at secondary schools when learners exchange their written task thus underlining or correcting the errors. But correction of the spoken language is considerably rarely carried out and usually is not quite successful. The tips suggested below will contribute to peer correction, as this experience has proved to be a successful one.

The purpose of the article is to describe a strategy used in peer correction which serves as a motivation for listening, asking questions and critical thinking.

It is an evident fact that improvement of any skill is achieved through working hard over that very skill, thus through reading a learner is getting used to memorizing new words, idioms, collocations, terms necessary for a separate branch of science. If the student wills to comprehend a foreign language he has to listen to a native speakers' speech, various tapes, watch films, etc. Writing abilities are gained through writing essays, letters, picture descriptions and even short stories.

Thus, speaking is not exclusion either. In order to speak a good foreign language the only way is active speaking. Students may start with short dialogues or monologues. Either way is appreciated. Through speaking they try to express their opinion, agreement or disagreement or by retelling or speaking on any topic they improve coherence, which is of not less significance as well.

There are lots of speaking tasks. And one of the ways experienced at my classes was the involvement of students in the speaking process.

It is evident that learners are usually not eager to listen to one another's speech, especially when some of them speak in a monotonous and boring manner, as if trying to swiftly complete their speech and take a seat. All the instructions serving to make the learners listen to the speaker occasionally fail. To make this process attractive, the students are suggested to correct one another's mistakes. 
Variety of errors turns the process of correction from a merely boring activity into an interesting one. By variety of errors we mean a broad range of mistakes including the use of the wrong article, preposition, singular and plural of nouns, tenses, the verb to be, the third person singular in simple present tense, irregular verbs, word order, etc. The last one is especially challenging as far as in the Azerbaijani language the word order is compiled in such a way that the subject of the sentence stands at the beginning of the sentence, while the place of the predicate is mainly at the very end of the sentence. The place of all the secondary members of the sentence is between principle parts of the sentence i.e. subject and predicate. Thus, translating a sentence from the native language into English orally, one must wait for the whole sentence to be completed in order to place the predicate in its second position in English.

When the students are first suggested to correct each others' mistakes in most cases they hesitate or even try to avoid it. The first reaction is always the feeling of bewilderment or perplexity.

On the one hand the teacher's instruction is to be fulfilled, on the other hand student solidarity outweighs. They are occasionally puzzled with the teacher's offer and accept it as betraying one another. In my practice in several cases close mates refused to correct each other's errors.

But the situation drastically changes as soon as the learners are told that they will get points for each correction, even more points if only one student in a group finds out a mistake. The more mistakes the learners correct, the higher points they get.

An encouraging point in peer correction has been achieved when it was announced that the instructor has no intention to lower the speaker's point. As a proof the teacher may announce the speaker's mark immediately after the speech is completed, which by no means will be lowered. The teacher's role here is to take notes together with listeners, analyze all the pros and cons that are worth reminding. And the number of instructor's notes are undoubtedly expected to surplus the students' corrections.

Another significant point is that the speaker should not be interrupted. While listening to their mate the learners may take notes, put down controversial points in each other's speech. In any speech the students may encounter unknown words, especially if the retold material is taken from supplementary sources, i.e. newspaper materials, scientific articles from journals etc.

The students are suggested to make a list of phonetic, grammar, lexical, sentence structure mistakes; appreciate vocabulary range, fluency, appropriate coherence, precise use of language constructions. Making up a table with speakers' names, above mentioned types of mistakes and remarkable pres provides an opportunity to clearly differentiate each speaker's success. Since the students-listeners are not only the ones who critically take notes looking forward to hearing mistakes. In order to encourage the speaker they should mention positive points in the speech. Uttered new words, terms, collocations, or the main idea presented to their attention are appreciated. Applying point system in evaluation is recommended from the point of view of effectiveness. Hence it contributes to the students' grasping the new information, they get used to a foreign speech presented by various people, comprehending through listening, differentiating correct and wrong pronunciation, spelling and reading the words, especially the unknown ones and at last critically expressing their opinion, trying to defend their opinion, which leads to skilful maintenance of discussion and polemics. These skills will be beneficial for them in their future participation at the conferences. They should be able to stand for their ideas.

Another advantage of this technique is that it gives a hint to an instructor how successfully the topic has been delivered. In some cases students cannot catch any error, though listen attentively, then it serves as a signal to a teacher that the topic or grammar rule should thoroughly be explained again. In practice there may arise a situation when corrector can so be involved in correcting process that will correct even the right version. And if the speaker does not refute it is time for the instructor to immediately interfere. Having asked the learners' opinion he should deliver the explanation, otherwise the students will be confused and may accept the wrong for the right.

Though some experts repetitively recommend not to correct errors and let the learners speak the way they are able. But not correcting the errors will lead to fossilizing them in memory.

Chasing mistakes helps the students be more attentive, not to repeat the same error and avoid fossilization i.e. occurrence of repetitive errors lasting long. Further in their second or third months the frequency of mistakes lessens and here the next stage starts. The students get more focused on the main idea, its purpose and new vocabulary. And the progress is evident - formerly not welcomed offer turns out to be accepted with great enthusiasm, thus changing teacher-oriented method into student-oriented technique as well. The fewer the number of students with presented mistakes, or the more the quantity of the errors discovered, the higher is the point. 
Errors mostly appear when the speaking activity of presenting a ready-made material is over and the learner either answers the additional questions or tries to clarify the matter in his own way. And if this is beyond his current level of knowledge the error is unavoidable. Mistakes may arise in the form of slips. And they can be mostly corrected by the speaker himself. For most Azerbaijani learners English has long been the third foreign language after Russian. Nowadays English has taken the revenge and has become the second one. It has advantages and disadvantages. On the one hand the more languages one knows, the easier it becomes to learn the following one, though in our case all three languages belong to various groups of families. English being an Indo-European language belongs to the West Germanic group of the Germanic languages. Russian belongs to the East Slavic group of the Slavic branch of the Indo-European language family. And our native Azerbaijani is one of the Oghuz languages within the Turkic language family. This fact adds even more complications to learning a foreign language. In our case Azerbaijani being native and Russian being the second language, both profoundly influence the comprehension process. Thus, overgeneralization which is widely encountered in teaching process at secondary schools is not an exception at the university level as well. Students may occasionally apply studied grammar rules inappropriately. It would be suitable to remind the axiomatic that the greater the student's individual effort, the more thorough will be his learning.

Conclusions. The existence of the tempting element in this process may not be accepted by some methodologists, but the experiment does work and displays that students get more involved in this process, they lively react at every single wrong utterance be it grammar, vocabulary or pronunciation mistake. Evident enthusiasm proves this method to be successful.

Experts are usually insistent on not interrupting the learners' speech, not interfere during their presentation. But in reality it is impossible to follow this instruction. The matter is some learners repetitively make one and the same error several times which leads to fossilization. And even worse other learners accept it as the correct one. Such repetitive errors should immediately be corrected.

Learning a foreign language is a rather challenging and long process and errors arising during learning are a natural and inseparable part of this process. The fact that through corrections the learner improves his language skills is evident.

This strategy allows the students to improve interpersonal and communication skills, consequently preparing them for public speaking.

\section{REFERENCES}

1. Fitikides T.J. Common Mistakes in English. Longman,Enland, 2002

2. Mary Spratt, Alan Pulverness, Melanie Williams The TKT course. UK, Cambridge University Press. 2013.

3. Vladimir Voytenok,Alexander Voytenko, Conversational English. Airis Press Rolf, Moscow, 2001

4. Peter redman Good Essay Writing A social sciences Guide, Sage Publications, London, 2003

5. Janet Whitcut, Sidney Greenbaum, Guide to English Usage Longman ,1990

6. Kaushanskaya V.L., Kovner R.L., Kojevnikova O.N., Grammar of the English Language. Leninqrad, 1988

7. В.В.Аракин. История английского языка Просвещение, Москва, 1985 